\title{
O PROJETO GRÁFICO EM SUPERFÍCIES AZULEJARES: UM ESTUDO DE CASO SOBRE AZULEJOS EM CAMPINA GRANDE - PB
}

Víctor Veríssimo Guimarães

Universidade Federal de Campina Grande

victorverissimo@live.com

José Eustáquio Rangel de Queiroz

Universidade Federal de Campina Grande

rangeldequeiroz@gmail.com

Alcília Afonso de Albuquerque e Melo

Universidade Federal de Campina Grande

kakiafonso@hotmail.com

Resumo: O presente artigo tem como objeto de estudo superfícies azulejares, uma alternativa construtiva/decorativa para edifícios que, ao longo do tempo, adaptou-se a diversos contextos culturais e se tornou uma referência de representação de várias culturas. Objetivou-se, por meio deste estudo, analisar esse tipo de superfície a partir de requisitos específicos da linguagem visual adotada em projetos gráficos. Como estudo de caso, foram selecionados dois exemplares de azulejos encontrados na cidade de Campina Grande, ambos pertencentes a edificações de linha estilística modernista. A abordagem de estudo adotada justifica-se pela reduzida quantidade de pesquisas relacionadas ao contexto apresentado, bem como pela crescente importância dos princípios de design da interação no desenvolvimento de produtos. A metodologia utilizada fundamenta-se na análise da imagem do painel azulejar como uma mensagem compreendida entre a expressão e a comunicação, em que devem ser considerados os elementos constituintes para se definir um contexto, conforme Joly (2015). Para a construção do aporte teórico, tomou-se como referência as definições de Design de Superfície de Rüthschilling (2002), reafirmadas em Schwartz (2008), bem como os estudos de Dondis (2007), acerca da sintaxe da linguagem visual e de Wong (2014), sobre os princípios da forma e do desenho.

Palavras-chave: Linguagem Visual, Superfície, Painel Azulejar

Abstract: In this paper, we provide a study on tiled surfaces as a constructive/decorative alternative for buildings that over time has been adapted to different cultural contexts and has become a representation reference for several cultures. The purpose of this study is to analyze this type of surface from specific requirements of visual language in graphic design. As a case study, we chose two tile patterns, both found in Campina 
Grande (PB) on residential buildings belonging to modern architecture. The methodological approach adopted for this study is justified by the reduced amount of researches relating the variables considered as well as by the growing importance of interaction design principles on product development. Based on the analysis of the tile panel image as a message between expression and communication, the methodology considers context elements, according to Joly (2015). he theoretical framework taken as a reference the Surface Design settings worked by Rüthschilling (2002) and reaffirmed by Schwartz (2008) as well as studies of Dondis (2007) about the syntax of visual language and Wong (2010).

Keywords: Visual Language, Surface, Tile panel

\section{INTRODUÇÃO}

Antes de se compreender o caráter morfológico do objeto de pesquisa cabe-se inicialmente entender o significado das variáveis do termo Superfície Azulejar. Primeiramente, deve-se esclarecer que o produto azulejo se define como um subproduto da cerâmica, caracterizado segundo Simões (1990) pela destinação decorativa, cuja aplicação, como revestimento, é feita sobre superfícies parietais e pavimentares.

Nessa perspectiva, sabe-se que os primeiros registros desse tipo de produto remontam à organização das primeiras civilizações, não havendo ao certo, consenso sobre os precursores. Cavalcanti (2002) presume que a invenção ocorreu entre os mesopotâmicos, cuja motivação, inicialmente, era a proteção contra a umidade, ganhando com o tempo valores decorativos, ficando a utilidade prática para segundo plano.

No âmbito da trajetória histórica da humanidade, o azulejo assumiu diversas formas de utilização e tipologias de representação, de modo que, por exemplo, segundo Fanning e Jones (2001), durante a Idade Média seus padrões decorativos serviram de adorno em fontes e pátios do Oriente. Por outro lado, na Europa, a partir do século XIII, difundiu-se um padrão decorado e policromado empregado na decoração de palácios reais e nos templos religiosos. Vale ressaltar que foi em Portugal que esse produto teve maior destaque, tornando-se instrumento de identidade cultural, assimilado por suas colônias, a exemplo do Brasil.

Neste sentido, a presença da azulejaria nas fachadas representa uma parte importante da história das formas de construir e morar, sendo que assume além de suas funções, uma essência cultural, servindo como meio de compreensão da organização das sociedades locais e suas economias.

O dicionário Michaelis (2016) define superfície como a relação entre área $x$ face ou mesmo sinteticamente pela parte externa dos corpos. Em síntese, a natureza do termo superfície azulejar finda por ser associada ao elemento aparência do azulejo. Assim sendo, tomou-se como base no presente estudo o elemento e, mais especificamente, os padrões figurativos característicos da superfície azulejar, no intuito de se compreender como os elementos que compõem a linguagem visual funcionam e se organizam em um painel azulejar. Mesmo tratando-se de uma 
perspectiva de estudo que envolve o design de superfície, preferiu-se utilizar uma metodologia de análise baseada no design gráfico, visto que o foco de interesse não recai nos aspectos constituintes do produto, mas apenas nos aspectos de representação da informação.

No decorrer deste documento, serão discutidas as linhas gerais de estudo referentes ao design de superfície que, serão confrontadas as especificidades superfície azulejar. Procurar-se-á também estabelecer relações entre as diretrizes definidas pelo design de superfície com os elementos da linguagem presente nos azulejos. Além disso, procurar-se-á estabelecer relações entre as características morfológicas dessas linguagens com a ação de usabilidade com usuário.

\section{CONTEXTUALIZAÇÃO}

\subsection{Design de Superfície: os tipos de abordagem e os princípios básicos de projeto}

De acordo com Schwartz (2008), é possível estabelecer, no âmbito do estudo do design de superfície, três grandes abordagens (Figura 1), a saber: (i) representacional, envolvendo a representação gráfica e a geometria; (ii) mais constitucional, referente aos materiais e aos procedimentos técnicos utilizados no processo de confecção de um produto; e, por fim, (iii) relacional, a partir da qual se estabelecem relações de qualquer natureza entre o sujeito, o objeto e o meio, quer de ordem semântica, cultural, ergonômica, produtiva ou mercadológica, dentre outras.

As três impactam, em maior ou menor intensidade, a configuração das características diretamente observáveis que definem a aparência final da superfície de um objeto, pois se integram, inter-relacionando-se.

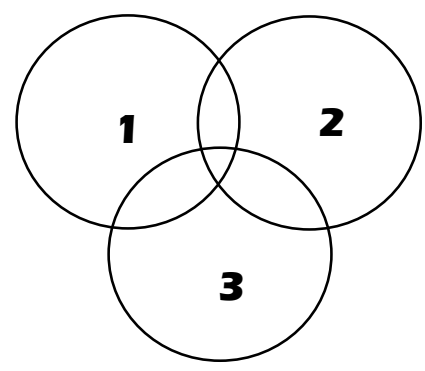

1. Face Representacional

2. Face Constitucional

3. Face Relacional

Figura 1- Faces de Abordagem de estudo do design de Superfície.

Fonte: Adaptado de Schwartz (2008).

Ressalta-se, neste sentido que, para este estudo, adotou-se exclusivamente a abordagem representacional porque, no caso dos azulejos, é a a componente se incorpora os padrões imagéticos e ilustrativos, sobre os quais se realizou o estudo.

No intuito de esclarecer particularidades dentro das superfícies, Rüthschilling (2002) delimita os princípios básicos de construção a serem seguidos em um design: (i) a composição, que se refere ao modo como se organizam os elementos; (ii) a utilidade, que trata da finalidade de criação de determinado processamento de superfície para um dado público-alvo; (iii) o conhecimento técnico, que focaliza o entendimento de técnicas e processos que poderão ser usados na fabricação do produto que está sendo criado (e.g., matrizaria, tecelagem, estamparia, serigrafia) e dos materiais (e.g., corantes, tintas, pigmentos, polímeros) para controlar os efeitos visuais desejados; e, 
por fim, (iv) a repetição, que corresponde à organização formal dos elementos contidos no desenho, em unidades ou módulos, gerando um padrão.

No âmbito específico do tratamento da repetição, Fachini (2015) determina três aspectos a serem considerados: o módulo, o encaixe e o sistema (Figura 2).

O módulo corresponde à unidade de padronagem, na qual se encontram estão todos os elementos do desenho organizados em uma estrutura pré-estabelecida, de forma que, dispostos lado a lado, formam um padrão contínuo. O sistema, por sua vez, diz respeito ao modo de repetição do módulo, podendo ser alinhado (em que as unidades modulares são posicionadas lado a lado e umas sobre as outras) ou não alinhado (quando os módulos não se mantêm em um único alinhamento). O encaixe, por fim, é o estudo de como os pontos de encontro das formas se darão, a fim de estabelecer um desenho contínuo.

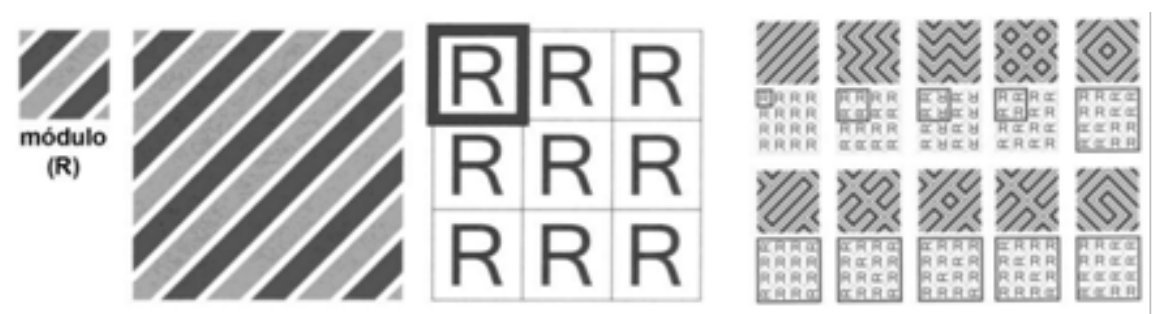

Figura 2- Rapport de listras e resultados de efeitos, conforme o posicionamento dos módulos. Fonte: Suono (2013)

No que se refere à abordagem definida para este artigo, entende-se que algumas das propriedades naturais do design de superfície se mantêm, principalmente no tocante à utilidade, aos conhecimentos técnicos e aos materiais. A superfície material do azulejo é composta por óxidos metálicos refratários, sejam naturais ou artificiais, que podem ser utilizados isolados ou em misturas. Sua utilidade é decorativa, bem como de resistência, pois também visam a elevar a dureza do azulejo como um todo. Quanto ao conhecimento de produção, percebe-se a assimilação da técnica de mimetização, desde o início do século XX.

Buscar-se-á, a partir das análises conduzidas no decorrer desta publicação, entender a composição azulejar, a partir de referências específicas do design gráfico. Isto constitui o objetivo geral deste estudo, bem como a inclusão do estudo da repetição, propriedade própria do design de superfície.

\subsection{Os elementos da Linguagem Visual e as formas de organização}

É compreensível que a produção de qualquer artefato gráfico envolva indistintamente a presença de elementos visuais gráficos. Confirmando esta idéia, Dondis (2007) declara que os elementos visuais representam a essência básica daquilo que se vê, estes se resumem à seguinte sequência: ponto, linha, forma, direção, tom, cor, textura, dimensão, escala e movimento.

Segundo Wong (2010), a linguagem visual constitui a base de criação de qualquer desenho, na qual são encontrados princípios, regras ou conceitos relacionados à organização de elementos específicos. Tais elementos podem ser distinguidos de quatro formas, a saber: (i) conceitual, relacionada aos elementos que não existem na realidade, porém parecem estar presentes - ponto, linha, plano, volume; (ii) visual, 
correspondente àquilo que se pode ver de fato frente aos elementos conceituais forma, tamanho, cor e textura; (iii) relacional, referente à localização e às interrelações entre os formatos do desenho - direção, posição, espaço e gravidade); e, finalmente, (iv) prática, relativa ao conteúdo e à extensão do desenho representação, significado e função.

Para a análise conduzida neste estudo foram considerados os elementos de ordem visual e relacional. Os elementos conceituais não serão considerados por já estarem contemplados essencialmente no estudo visual, bem como os elementos práticos, por preverem a necessidade de interação com usuários/observadores.

\section{MÉTODOS E TÉCNICAS}

Antes de se proceder a discussão do método de análise a ser adotado neste estudo é importante salientar que o design gráfico está intimamente vinculado ao design de superfície. Antropologicamente falando, segundo Zorgi (2008), a primeira expressão gráfica deu-se possivelmente sobre uma pedra. Logo, o designer gráfico não pode prescindir da superfície, uma vez que esta pode influenciar a qualidade do produto final.

Assim sendo, é necessário considerar-se a dimensão dedicada à superfície, de maneira que deve ser entendida como variável de projeto, a fim de entendê-la no contexto de suas limitações e vantagens em relação ao produto em questão.

Quanto à metodologia de análise, entende-se que uma obra visual permite inúmeras possibilidades de interpretação e discussão. Dondis (2007) pontua que uma das maneiras mais reveladoras de compreensão visual é a decomposição em seus elementos constituintes. Muito antes dele, Fontoura (1982) já propunha um método de entendimento do todo visual a partir da compreensão de 3 aspectos do desenho: 0 físico, o psicológico e o semiológico.

Em meio a essas possibilidades, preferiu-se utilizar a abordagem proposta por Joly (2015), a partir da qual se pode interpretar a imagem a partir da organização de seus eixos plásticos - a forma, as cores, a composição e a textura. Tais eixos coincidem com os elementos propostos por Wong (2013) na caracterização visual do desenho. Assim sendo, as abordagens de ambos os autores foram utilizadas como suporte à análise conduzida neste documento.

A análise dessas particularidades morfológicas nos azulejos é de fundamental importância, pois possibilitam a definição dos requisitos específicos do artefato sob o ponto de vista do usuário. Segundo Manzini (1993), as superfícies são interfaces entre usuários e objetos, por meio das quais as qualidades da superfície determinam a seleção de estímulos disponíveis no espaço visual. Elementos diferenciados por cor, textura e forma ou aqueles que se relacionam diretamente com os objetivos específicos do assunto serão os pontos focais de atenção.

Para o caso de estudo, a metodologia foi adequada à análise de dois painéis de azulejos encontrados em edificações de linha construtiva e estilo moderno, na cidade de Campina Grande (PB). 


\section{ANÁLISE DAS SUPERFÍCIES AZULEJARES}

O corpus de análise a ser apresentado toma por base o método anteriormente descrito, no intuito de se interpretar os eixos plásticos e os requisitos específicos do usuário dos desenhos de dois painéis de azulejo situados em edifícios da cidade de Campina Grande. Para melhor compreensão preferiu-se dividir este item em três tópicos: o primeiro tratando das características plásticas do painel encontrado na Residência Hélion Paiva, o segundo referente as características plásticas do painel do Edifício Prata, e, finalmente o terceiro das condições ergonômicas dos painéis para com os usuários.

\subsection{Residência Hélion Paiva}

Situada na Av. Floriano Peixoto, a residência projetada pelo Arquiteto Geraldino Duda, em 1968, apresenta um dos muros laterais totalmente recoberto por um painel de azulejos, sobre o qual se procederá a primeira análise.

Visando ao melhor entendimento, tomou-se o azulejo como objeto unitário de observação, um módulo original e indissociável. Inicialmente, cabe caracterizá-lo pelo uso de formas construídas enquanto plano, visto que estas se limitam por linhas conceituais. Tais formas seguem uma ordenação orgânica, sendo caracterizadas pelo uso de curvas livres que sugerem fluidez e irregularidade. (Figura 3).
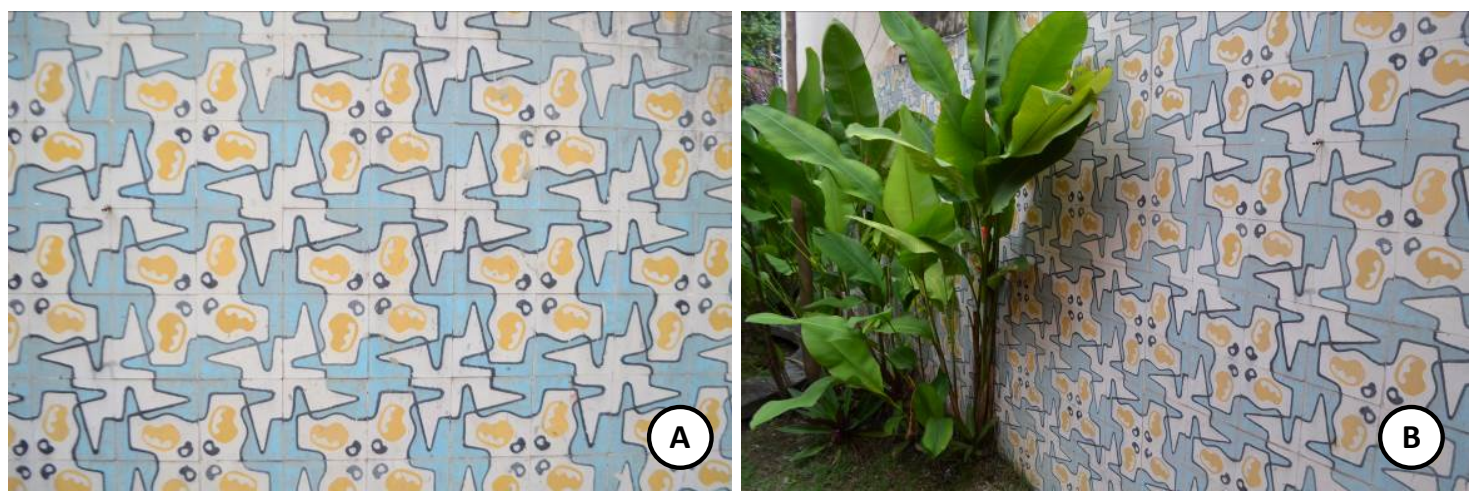

Figura 3 - Painel azulejar da Residência Helión Paiva: A detalhe; e B integração ao contexto paisagístico da residência.

Fonte: Acervo fotográfico de Víctor Veríssimo.

Dissecando-se o módulo, podem-se encontrar 9 formas diferentes (Figura 4). Entre as formas 1-2, 1-3, 2-4 e 3-4 ocorre interrelação por contato, visto que estas não se tocam somente pela existência das linhas divisórias. Entre 1-4, ocorre interrelação por intersecção, uma vez que há um ponto de cruzamento entre as formas. Em contrapartida, entre as formas 4-5 e 4-7, existe uma interrelação por superposição, tendo em vista uma encontrar-se sobre a outra. Finalmente, entre as formas 5-8 e 7-9, observa-se uma interrelação por subtração, pois uma forma invisível está superposta sobre outra visível. Esta constatação é reforçada pelo fato da base natural azulejar ser branca. Ressalta-se que as demais possibilidades de relação se dão por separação. 

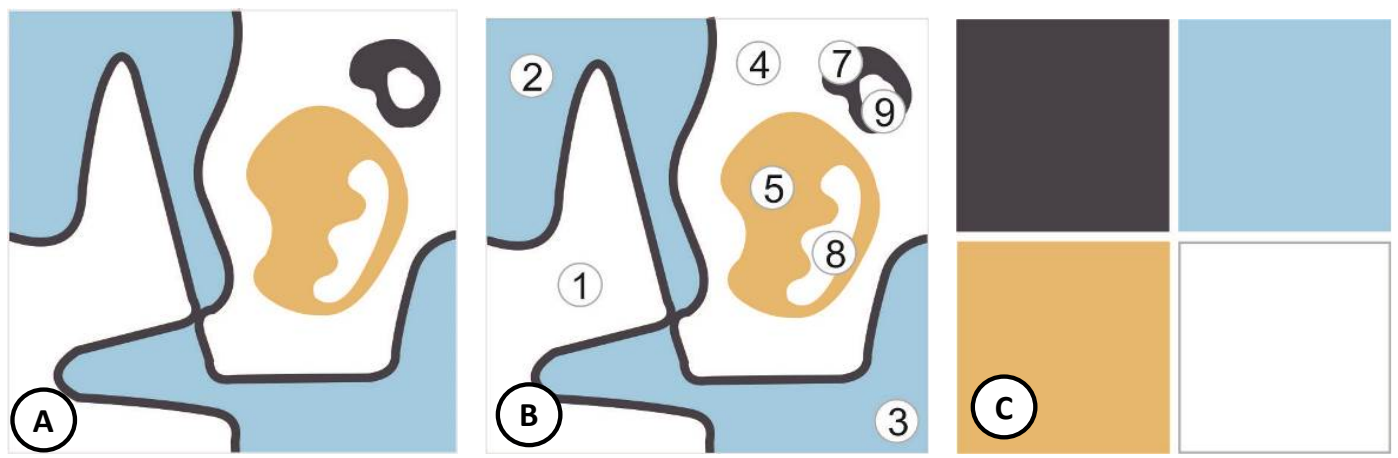

Figura 4 - Módulo azulejar da Residência Helión Paiva: A Projeto gráfico; B Planos existentes; e C Cartela Cromática. Fonte: Adaptação realizada pelos autores.

No tocante à composição, entende-se que a forma gráfica é dinâmica, visto que não há previsibilidade quanto à forma nem à disposição e semiformal, pois as formas não seguem linhas ordenadoras, com exceção dos pontos de origem das linhas que se encontram sobre o mesmo ponto de eixo (de abcissas e ordenadas) nas faces opostas.

Sobre as cores, observou-se o uso de quatro cores uniformes, sendo duas decorrentes da variação do matiz azul - uma mais quente (clara - R151 G205 B231) e outra mais fria (escura - R74 G76 B89), uma variante do matiz amarelo (R233 G191 B119), além do branco (RO G0 B0). O predomínio da cor azul sobre a extensão da área branca (negativa) do módulo confere um aspecto gélido ao azulejo, quebrado apenas pelo uso da forma amarelo, de propriedade quente, que termina por servir de atração de foco visual na peça (Figura 4C).

Quanto à textura, entendendo-a como uma característica da superfície da forma, pode-se deduzir que a peça apresenta uma textura estritamente decorativa, visto que a superfície permanece subordinada à forma.

Finalmente, no tocante à compreensão da aplicação dos azulejos em meio a um conjunto, formando o painel, observou-se a repetição, um requisito próprio do design de superfície. Neste sentido, constata-se a existência de um sistema não alinhado. Logo, os módulos não se replicam em um único alinhamento.

Para a apreciação dos sistemas de encaixe dos módulos no painel, o plano cartesiano foi utilizado, a fim de possibilitar o entendimento de como os módulos e supermódulos se rotacionam, considerando-se o sentido anti-horário. O termo supermódulo é empregado neste estudo, quando os 4 módulos se agrupam em repetição conjunta, totalizando 16 módulos agregados. No caso em análise, o sistema rotacional de definição de encaixe ocorreu conforme ilustrado na Figura 5.
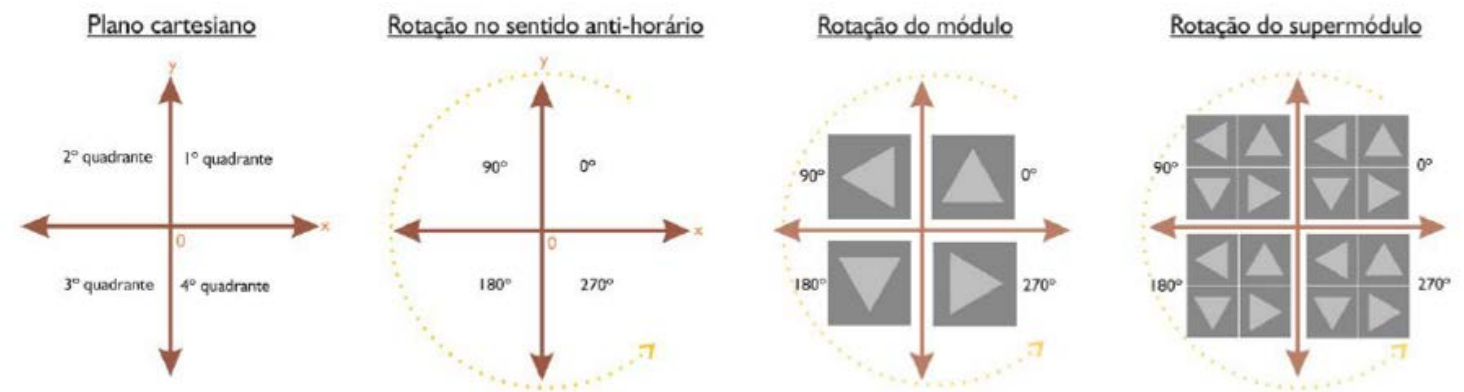

Figura 5 - Organização do sistema de organização de encaixe de módulos e supermódulos. Fonte: Adaptação realizada pelos autores. 
O módulo em cada quadrante varia sua orientação de maneira ortogonal, estabelecendo 4 posições diferentes no plano cartesiano (Figura 5). A figura formal termina por ganhar uma unidade por conta do caráter formal compositivo que apresenta pontos de contato coincidentes entre os quadrantes.

Em relação aos supermódulos, observa-se que sua sistematização é alinhada e sua repetição se dá, no plano cartesiano, em apenas um único alinhamento. Observase, adicionalmente que, nos módulos, os pontos de contato também coincidem, gerando outro parâmetro formal unitário.

\subsection{Edifício Prata}

A segunda aplicação azulejar analisada trata do painel encontrado no hall de entrada do Edifício Prata, localizado na Rua Simeão Leal, no centro de Campina Grande (PB), o qual foi projetado pelo arquiteto Augusto Reynaldo, no início da década de 60 (Figura 6).
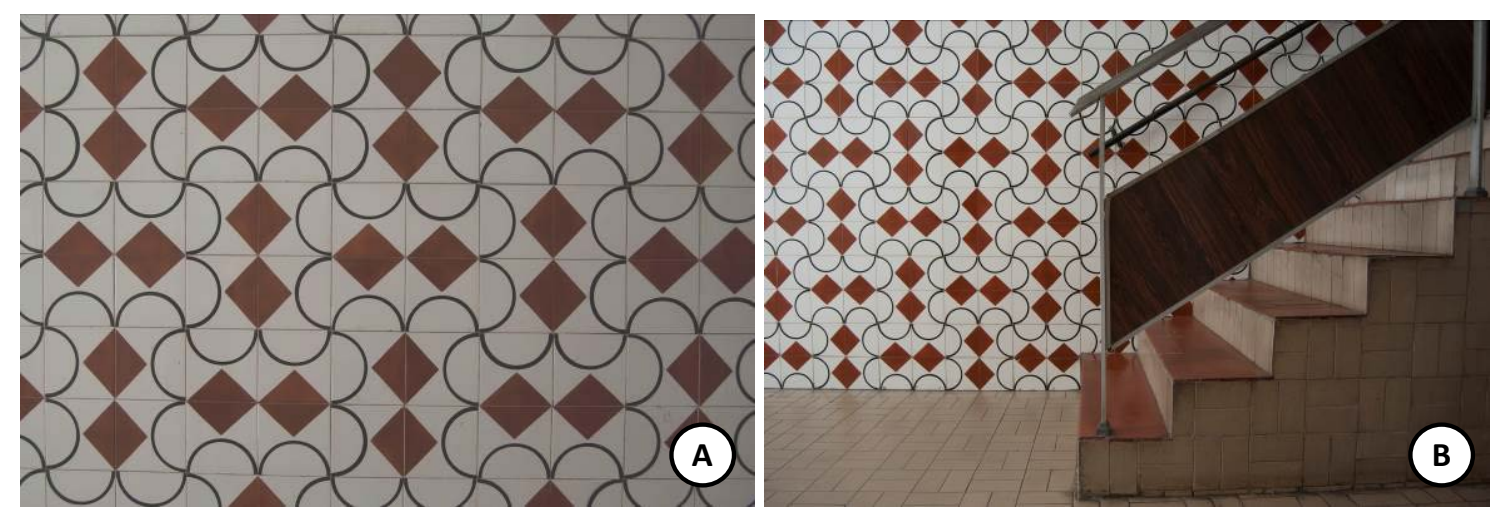

Figura 6 - Painel azulejar do Edifício Prata: A detalhe; e B integração ao arranjo edilício.

Fonte: Acervo fotográfico de Víctor Veríssimo.

Para exemplo, observa-se a utilização da forma de duas maneiras, como linha e como plano. Como linha, apresenta a forma apresenta um formato semicircular, um corpo compreendido entre bordas paralelas e extremidade ortogonal. Já como plano, apresenta uma construção geométrica, onde as relações matemáticas de posição são perceptíveis (Figura 10).

Ao todo, percebem-se três formas básicas, que podem ser diferenciadas pelo uso das cores. Estas se relacionam apenas de duas formas: 1-2 por separação, visto que não há contato entre as mesmas; e 1-3 e 2-3 por superposição, logo que as formas coloridas encontram se sobre o plano branco (Figura 11). 

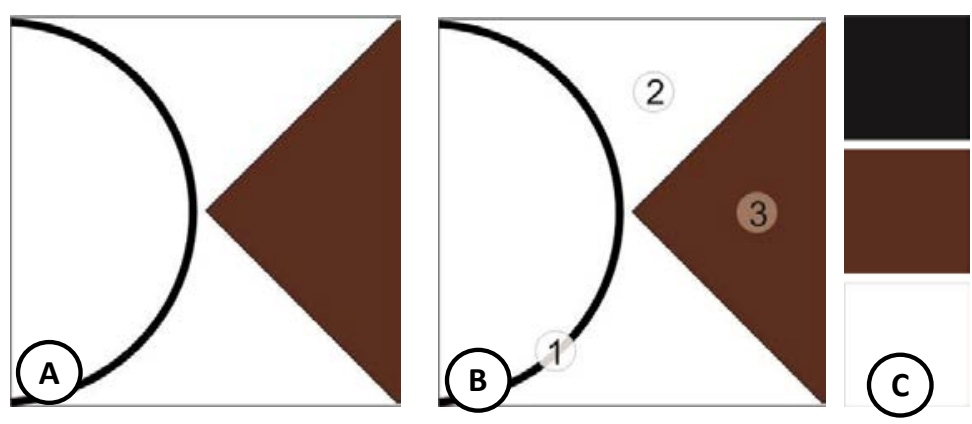

Figura 7 - Módulo azulejar do Edifício Prata: A Projeto gráfico; B Planos existentes; e C Cartela Cromática.

Fonte: Adaptação realizada pelos autores.

Quanto à composição, cabe-se destacar sua característica rígida e formal, pois a construção se sustenta a partir de linhas estruturais: um triangulo isósceles e um semicírculo. Nas cores, apreende-se a existência de três matizes: uma nuance de castanho avermelhado, uma preta e outra branca. $\mathrm{O}$ uso de tons escuros termina por criar uma atmosfera séria e fria (Figura 7C).

Assim como na análise do padrão anterior, a peça apresenta uma textura estritamente decorativa.
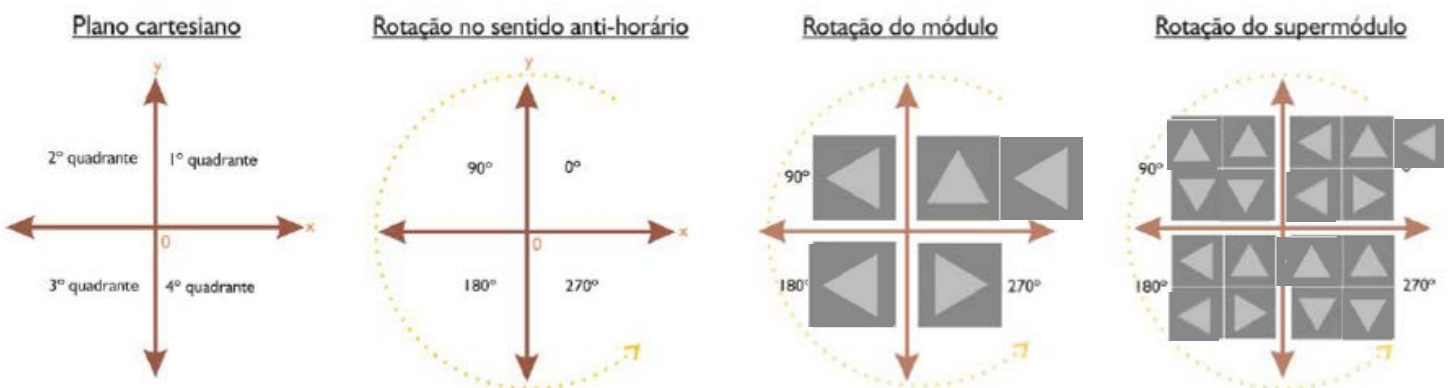

Figura 13 - Organização do sistema de organização de encaixe de módulos e supermódulos.

Fonte: Adaptação realizada pelos autores.

No aspecto de repetição, observa-se a existência de um sistema não alinhado, visto que contém mais de uma orientação. O sistema de encaixe se difere daquele existente no painel anteriormente analisado. Em meio aos módulos, existe uma disposição simétrica em relação aos eixos do plano cartesiano, de forma que os pontos de extremidade coincidem. No caso dos supermódulos, ocorre a rotação em $90^{\circ}$ entre o $1^{\circ}$ e $2^{\circ}, 2^{\circ}$ e $3^{\circ}, 3^{\circ}$ e $4^{\circ}$ e $4^{\circ}$ e $1^{\circ}$ quadrantes.

\subsection{As superfícies azulejares e as condições de ergonômicas}

Segundo Porter (1982), bem como de acordo com Mollerup (2005), a utilização ergonômica de cor, texturas e padrões gráficos pode auxiliar o projetista no destaque de detalhes, na quebra da monotonia por meio da introdução de ritmo e proporção, no aumento da legibilidade espacial, possibilitando a discriminação de volumes, na concepção de figuras, possibilitando a hierarquização de espaços e a orientação do observador, assim como a melhoria do processo de tomada de decisão de tarefas que se mostram aos sentidos. 
Deste modo, valendo-se dos painéis analisados, fazem-se algumas considerações fundamentadas nos pontos de vista de Porter (1982) e Mollerup (2005).

Quanto à cor, em ambos os casos a variedade e a diferenciação cromática dentro dos padrões favorece a discriminação dos elementos gráficos e, consequentemente, a caracterização, a compreensão e a significação do espaço, por parte do usuário. Em relação à saturação, observa-se a utilização mais efetiva desta propriedade no painel do Edifício Prata (ver Figura 6A), pois causa menos confusão; logo, possibilita visualizar e compreender a informação de variações de tamanho e orientação das grades de forma mais imediata.

No tocante à textura, em ambas decorativa, não ocorre contribuição nem prejuízo para a compreensão espacial do todo pelo usuário, visto que não há diferenciação tridimensional nesse plano.

Os padrões visuais conquistados pelo uso da repetição e das técnicas de encaixe, nos dois painéis estudos, clarificam as relações de forma e de fundo, proporcionando maior visibilidade à distância, o que aumenta a gama de usuários/observadores que se beneficiam de sua utilização como revestimento, incorporando sinalização e prazer estético.

\section{CONSIDERAÇÕES FINAIS}

Explicitamente, é possível deduzir que o estudo da azulejaria permite inúmeras percepções. Para o estudo de caso apresentado, foi possível observar principalmente duas delas. A primeira, relacionada à morfologia da base visual do objeto. A outra, decorrente dos princípios de usabilidade, do ponto de vista do usuário/observador.

A partir da relação destas duas percepções, pôde-se apreender que a organização da estrutura de composição de um azulejo exerce forte influência sobre a satisfação emocional e sensorial do usuário para com o objeto, sendo esse o principal ponto de relevância deste estudo.

Outro ponto de destaque diz respeito à afirmação da possibilidade de se incorporar bases metodológicas da sintaxe visual de projeto gráfico à caracterização da aparência de revestimentos, fugindo ao padrão prático usual que subjuga o design gráfico somente às interfaces stand-alone e Web.

Por fim, face à diversidade de percepções discutidas, pretende-se como continuidade deste estudo realizar um aprofundamento sobre caráter relacional entre o produto (azulejo) e o usuário/observador, no intuito de entender e avaliar a influência dos elementos gráficos na usabilidade do produto.

\section{REFERÊNCIAS}

DONDIS, D. Sintaxe da Linguagem Visual. São Paulo.Livraria Martins Fontes, 2007.

FACHINI, R. Design de superfície: um estudo sobre o uso do desenho infantil na criação de padrões, para superfícies têxteis destinadas a ambientes infantis. 2015. Dissertação (mestrado). Centro Universitário Univates. Curso de Design. 
FANNING, J.; JONES, M. A arte e o Ofício do Azulejo. 1. ed. Lisboa, Portugal: Estampa, 2001.

JOLY, M. Introdução à análise da imagem. Campinas: Papirus, 2015.

MANZINI, E. A Matéria da invenção. CPD, Lisboa. 1993.

MICHAELIS, Dicionário. Disponível em:<http://michaelis. uol. com. br $>$. Acesso em 08 maio, 2016.

MOLLERUP, P. Wayshowing - A Guide to Environmental Signage: Principles \& Practices. Lars Muller Publishers, Baden. 2005.

PORTER,T. Architectural Color. Whitney Library of Design, New York. 1982.

RUTHSCHILLING, E. Design de superfície: prática e aprendizagem mediadas pela tecnologia digital. 2002. 187f. Dissertação (mestrado). 2002. Universidade Federal do Rio Grande do Sul. Curso de Pós Graduação em Informática da Informação.

SCHWARTZ, A. Design de superfície: por uma visão projetual geométrica e tridimensional. 2008. 216p. Dissertação (mestrado). Universidade Estadual Paulista. Curso de Pós Graduação em Design.

SIMÕES, J. Azulejaria Portuguesa no Brasil (1500-1822). Lisboa: Fundação Calouste Gulbenkian, 1990.

WONG, W. Princípios da forma e desenho. São Paulo. 2. Ed. Livraria Martins Fontes, 2014. 